\title{
Removal of ethidium bromide by carbon nanotube in aqueous solution: isotherms, equilibrium mechanism studies, and its comparison with nanoscale of zero valent iron as adsorbent
}

\author{
Fahimeh Najafi ${ }^{*}$, Mehdi Norouzi ${ }^{2}$, Karim Zare $^{3,4}$ and Ali Fakhri ${ }^{5}$
}

\begin{abstract}
The adsorption of ethidium bromide (EtBr) by single-walled carbon nanotubes (SWCNTs) and nanoscale of zero valent iron (NZVI) were investigated to assess its possible use as adsorbents. The effect of various factors, namely initial adsorbate concentration, adsorbent dosage, and contact time, were studied to identify adsorption capacity of SWCNTs and NZVI surfaces. The experiment demonstrated the maximum EtBr which was obtained at 5 min to attain equilibrium for SWCNTs and NZVI surfaces. Adsorption data were modeled with the Langmuir, Freundlichand, Temkin isotherms. Langmuir adsorption model was used for the mathematical description of the adsorption equilibrium, and the equilibrium data fitted very well with this model for both surfaces as adsorbents. The study showed that SWCNTs and NZVI surfaces could be used as new and efficient adsorbent materials for the removal of $\mathrm{EtBr}$ from aqueous solution. Also, the result showed that the SWCNTs were more effective than NZVI in the removal of EtBr from aqueous solution.
\end{abstract}

Keywords: Ethidium bromide; Single-walled carbon nanotube; NZVI; Removal; Isotherms; Kinetics

\section{Background}

Ethidium bromide (EtBr; 3,8-diamino-6-phenyl-5-ethylphenanthridinium bromide), commonly used in research laboratories as a stain for the visualization of nucleic acids in electrophoresis gels, is a toxic chemical and a potent mutagen [1]. When used in nucleic acid staining, ethidium bromide fluoresces a red-orange to pink color under ultraviolet light and with increased fluorescence when bound to double-stranded DNA. While it is not specifically regulated as a hazardous waste, the mutagenic properties may present health hazards and disposal concerns if it is not managed properly in the laboratory [2]. Adsorption has been found to be an effective and economical method with high potential for the removal, recovery, and recycle of pollution from the wastewater [3]. In this decade, the use of single-walled carbon nanotubes (SWCNTs) and nanoscale of zero valent iron

\footnotetext{
*Correspondence: fahimnajafi@gmail.com

'Department of Chemistry, Roudehen Branch, Islamic Azad University, Roudehen, Iran

Full list of author information is available at the end of the article
}

(NZVI) as a reactive medium for the treatment of toxic chemicals is one of the most significant techniques and has attracted a lot of attention because the iron metal is of low cost, low toxicity, is easy to get, and has good effectiveness and ability to degrading contaminants. Laboratory studies have demonstrated that SWCNTs and NZVI surfaces as adsorbents can effectively transform chlorinated solvents, organochlorine pesticides, organic dyes and heavy metals [4-11] into nontoxic forms. Nanoscale of zero valent iron has drawn great attention as an inexpensive and environmentally friendly strong reducing agent $[12,13]$. Addition of NZVI to oxygen-containing water results in oxidation of organic compounds [14]. Therefore, extensive efforts have been directed to assess the potential application of NZVI for the decomposition of organic pollutants in the wastewater. SWCNTs, ever since their discovery, have attracted extensive attention due to their unique properties. They have shown potential applications in many areas, such as conductive and highstrength composites. With the significant increase in production and use of SWCNTs, one major concern is the 

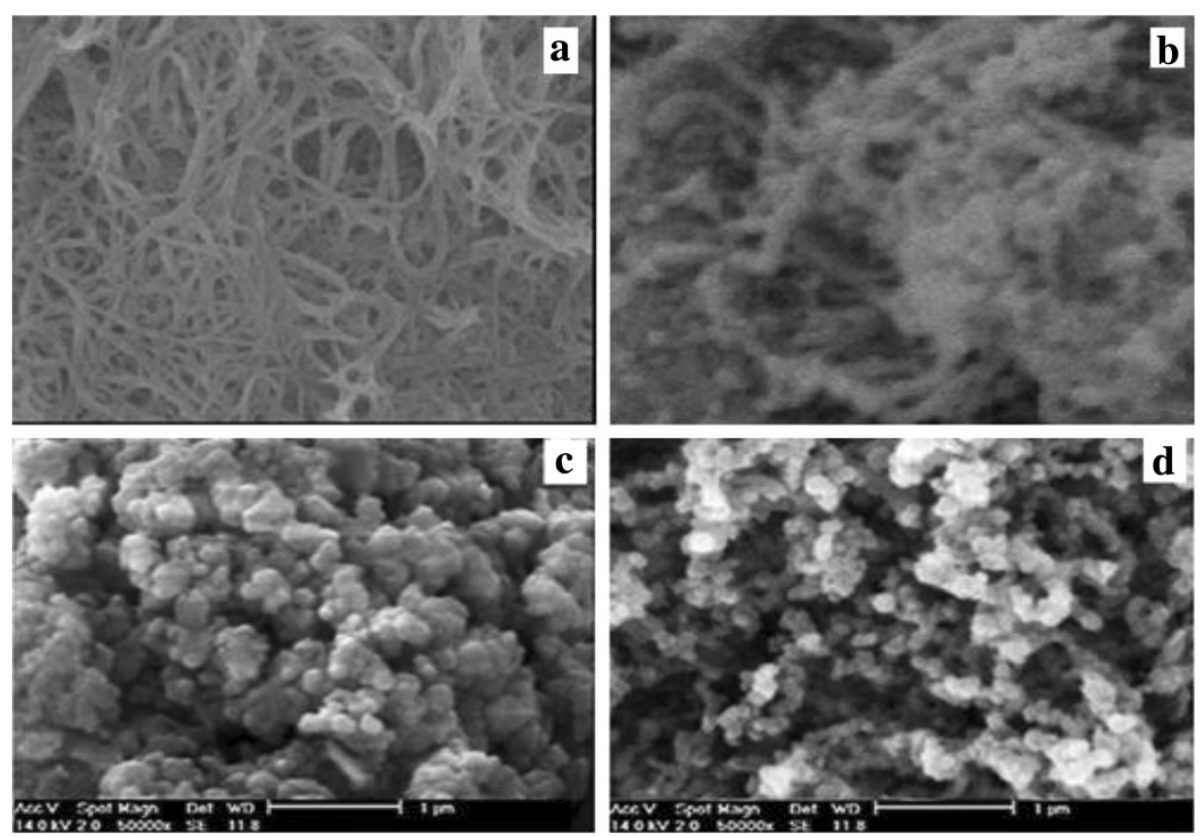

Figure 1 SEM images of SWCNT and NZVI surfaces before and after reaction. Before reaction (a,c, respectively) and after reaction (b,d,

respectively) with EtBr molecules in aqueous solution.

health and environmental risks posed by these nanomaterials once they are released to the environment. Evidences for potential risks of SWCNTs to humans and ecosystems are accumulating rapidly [15]. Due to their highly hydrophobic surfaces, SWCNTs exhibit strong adsorption affinities to synthetic organic chemicals, such as polycyclic aromatic hydrocarbons. As a consequence, toxicity of SWCNTs may be further enhanced by adsorption of toxic chemicals. Therefore, understanding of SWCNT interactions is critical for the environmental of both SWCNTs and toxic pollutants as well as for the applications of SWCNTs as potential adsorbents [16].

The objective of this research is to investigate the adsorption kinetics and isotherm models of EtBr removal by SWCNT and NZVI surfaces. Equilibrium data can be used to predict the rate at which the target contaminant is removed from aqueous solutions, and equilibrium adsorption isotherms are used to quantify the adsorptive capacity of an adsorbent. Results from this study can be used to assess the utility of SWCNT and NZVI surfaces for $\mathrm{EtBr}$ removal, in particular $\mathrm{EtBr}$ adsorption, at the field scale.

\section{Results and discussion}

\section{Characterization of the adsorbent}

Figure 1 shows the SEM image of freshly synthesized SWCNTs $(a, b)$ and iron nanoparticles $(c, d)$. It can be observed that the iron particles are in the form of nanospheres, which exist in contact with each other and form chains having diameters of 50 to $100 \mathrm{~nm}$ [17].

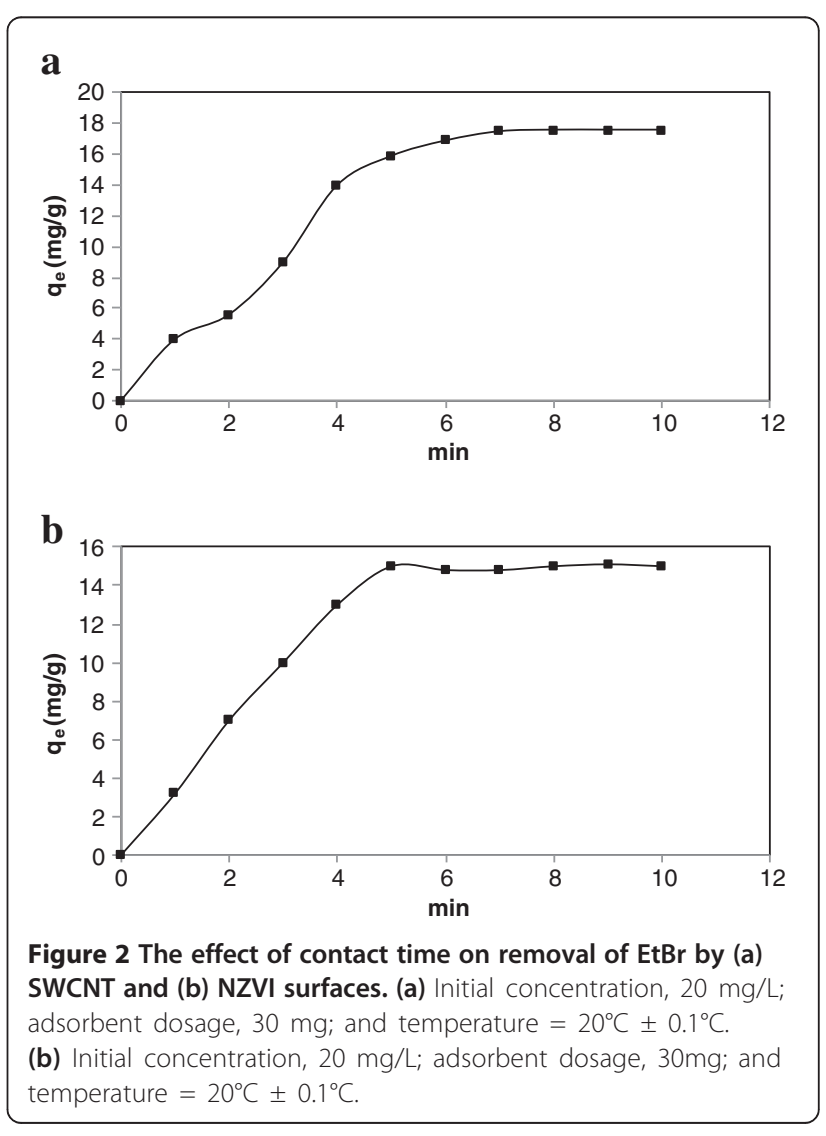




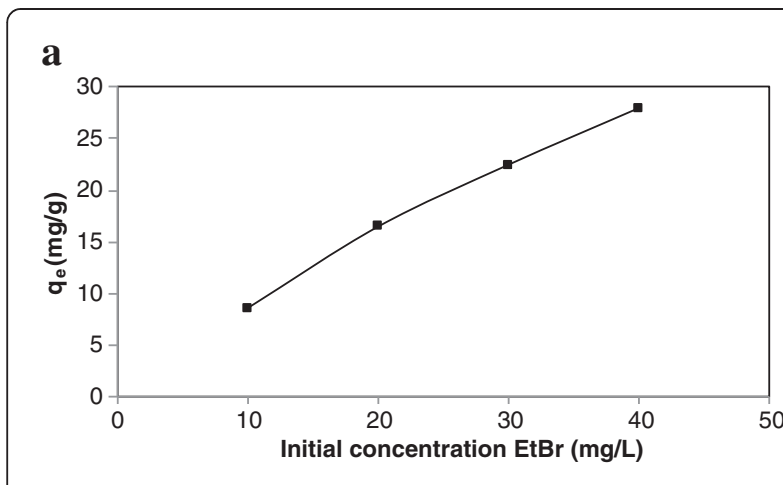

b

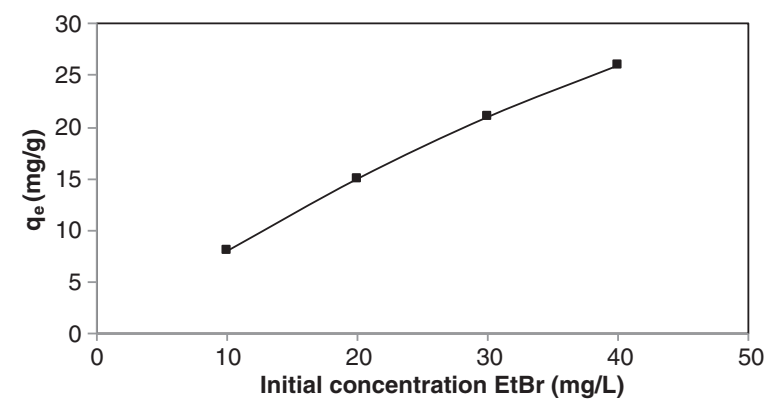

Figure 3 Effect of initial concentration on removal of EtBr by (a) SWCNT and (b) NZVI surfaces. (a) Contact time, 5 min; adsorbent dosage, $30 \mathrm{mg}$; and temperature $=20^{\circ} \mathrm{C} \pm 0.1^{\circ} \mathrm{C}$. (b) Contact time, $5 \mathrm{~min}$; adsorbent dosage, $30 \mathrm{mg}$; and temperature $=20^{\circ} \mathrm{C} \pm 0.1^{\circ} \mathrm{C}$.

Figure $1 \mathrm{~b}, \mathrm{~d}$ showed that the EtBr molecules removed by SWCNT and NZVI surfaces were covered in aqueous solution.

\section{Effect of contact time}

In these experiments, initial concentration of $\mathrm{EtBr}$ molecules on SWCNT and NZVI surfaces was $20 \mathrm{mg} / \mathrm{L}$ (Figure 2). The effects of contact time (0 to $10 \mathrm{~min}$ ) were investigated at $20 \mathrm{mg} / 50 \mathrm{~mL}$ sample dosage. The extent of removal of EtBr by SWCNT and NZVI surfaces was found to increase and has reached its maximum with the increase in contact time. The time at which the maximum percentage removal of $\mathrm{EtBr}$ occurs is fixed as the contact time (Figure 2a for the removal of SWCNTs and Figure $2 b$ for the removal of NZVI).

\section{Effect of initial EtBr concentration}

The effect of initial concentration (10 to $40 \mathrm{mg} / \mathrm{L}$ ) of EtBr adsorption on to SWCNTs and NZVI surfaces are presented in Figure 3 (Figure $3 \mathrm{a}$ for the removal of SWCNTs and Figure 3b for the removal of NZVI). A rapid removal is observed at the initial stages, and it then proceeds slowly until equilibrium is reached. This may be due to the availability of the number of vacant adsorption sites at the initial stage. The equilibrium adsorption capacity of SWCNT and NZVI surfaces were decreased as there is increasing concentration from 10 to $40 \mathrm{mg} / \mathrm{L}$. At lower EtBr concentration, the available adsorption sites are relatively high, and consequently, the $\mathrm{EtBr}$ species can easily find the accessible adsorption sites for both adsorbents (SWCNT and NZVI surfaces).

\section{Effect of adsorbent dosage}

From Figure 4 (Figure 4a for the removal of SWCNTs and Figure $4 \mathrm{~b}$ for the removal of NZVI), we see that the optimum dose of SWCNT and NZVI surfaces for the EtBr were $30 \mathrm{mg} / 50 \mathrm{~mL}$. Though at $40 \mathrm{mg} / 50 \mathrm{~mL}$, there is a slight increase in adsorption value, but if we get nearly the same result as we get at an adsorbent dosage of $50 \mathrm{mg} / 50 \mathrm{~mL}$, then going for $70 \mathrm{mg} / 50 \mathrm{~mL}$ will be expensive and there will be loss of adsorbent. It is obvious, with increasing the amount, what the active sites are for adsorption of three dyes.

\section{Effect of temperature}

To study the effect of temperature on the removal of $\mathrm{EtBr}$, the experiments were carried out at temperatures varying from 283 to $313 \mathrm{~K}$. It is revealed from Figure 5 (Figure 5a for the removal of SWCNTs and Figure 5b

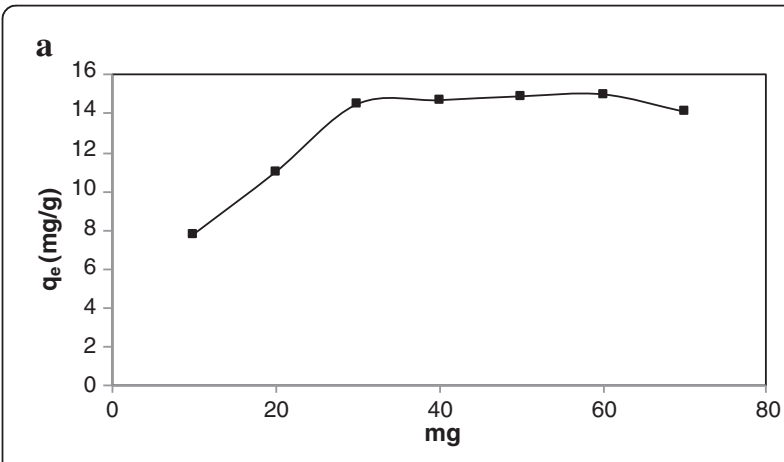

b

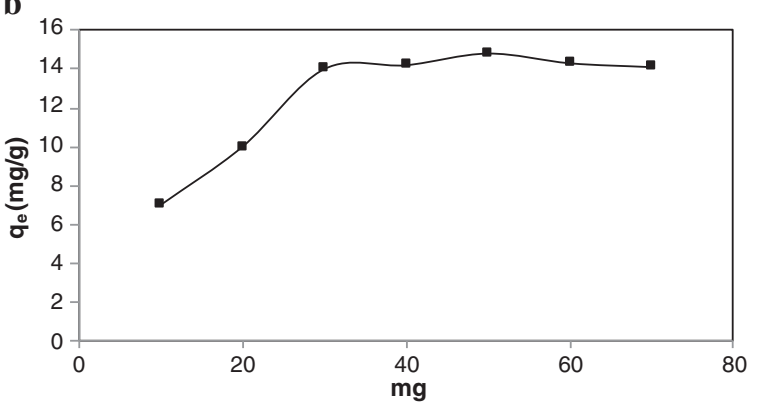

Figure 4 Effect of adsorbent dosage on removal of $\mathrm{EtBr}$ by (a) SWCNT and (b) NZVI surfaces. (a) Initial concentration, $20 \mathrm{mg} / \mathrm{L}$; contact time, $5 \mathrm{~min}$; and temperature $=20^{\circ} \mathrm{C} \pm 0.1^{\circ} \mathrm{C}$. (b) Initial concentration, $20 \mathrm{mg} / \mathrm{L}$; contact time, $5 \mathrm{~min}$; and temperature $=20^{\circ} \mathrm{C} \pm 0.1^{\circ} \mathrm{C}$. 


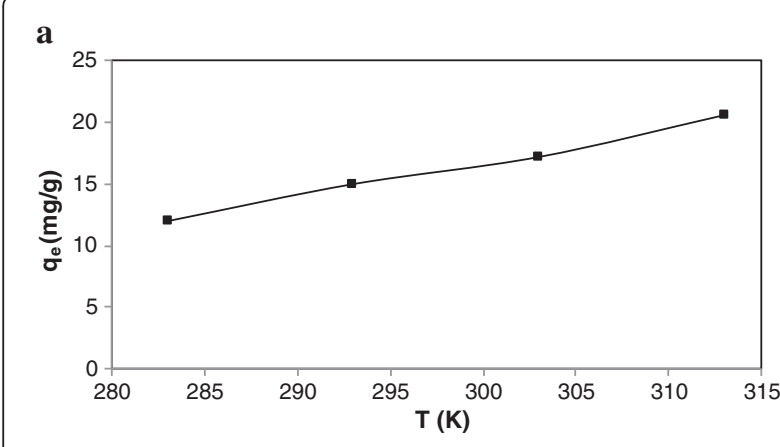

b

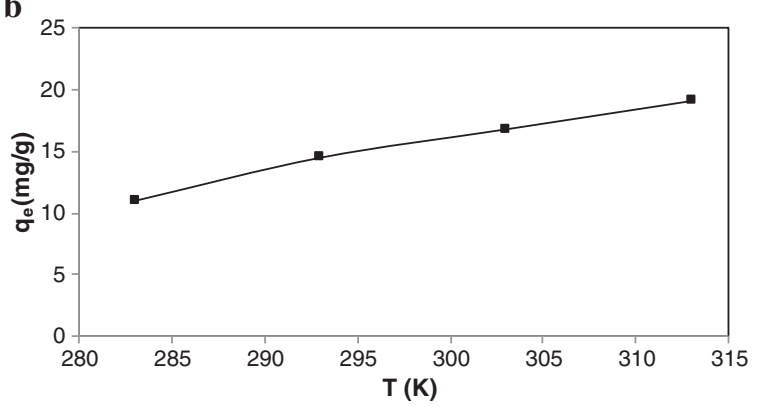

Figure 5 Effect of temperature on the removal of EtBr by (a) SWCNT and (b) NZVI surfaces. (a) Initial concentration, $20 \mathrm{mg} / \mathrm{L}$; contact time, $5 \mathrm{~min}$; and adsorbent dosage, $30 \mathrm{mg}$. (b) Initial concentration, $20 \mathrm{mg} / \mathrm{L}$; contact time, $5 \mathrm{~min}$; and adsorbent dosage, $30 \mathrm{mg}$. for the removal of NZVI), that the removal of EtBr with temperatures would increase the mobility of the $\mathrm{EtBr}$ and produce a swelling effect within the internal structure of adsorbent thus enabling the large molecules of $\mathrm{EtBr}$ to penetrate further. The greater removal of $\mathrm{EtBr}$ due to increasing temperature may have more interaction between the adsorbate and adsorbent.

\section{Adsorption isotherms}

Equilibrium isotherm equations are used to describe the experimental adsorption data. In this study, three adsorption models, that is the Langmuir, Freundlich, and Temkin isotherms, were used to describe the reactive dye equilibrium. The Langmuir isotherm [18] which is valid for monolayer sorption onto a completely homogeneous surface with a finite number of identical sites and with negligible interaction between adsorbed molecules is given by Equation 1:

$$
q_{e}=\frac{q_{m} K_{L} C_{e}}{\left(1+K_{L} C_{e}\right)}
$$

where $q_{\mathrm{e}}(\mathrm{mg} / \mathrm{g})$ and $C_{\mathrm{e}}(\mathrm{mg} / \mathrm{L})$ are the amount of adsorbed $\mathrm{EtBr}$ per unit mass of adsorbent and an adsorbed $\mathrm{EtBr}$ concentration in solution at equilibrium, respectively. $q_{\mathrm{m}}$ is the maximum amount of the EtBr per unit mass of adsorbent to form a complete monolayer on the surface
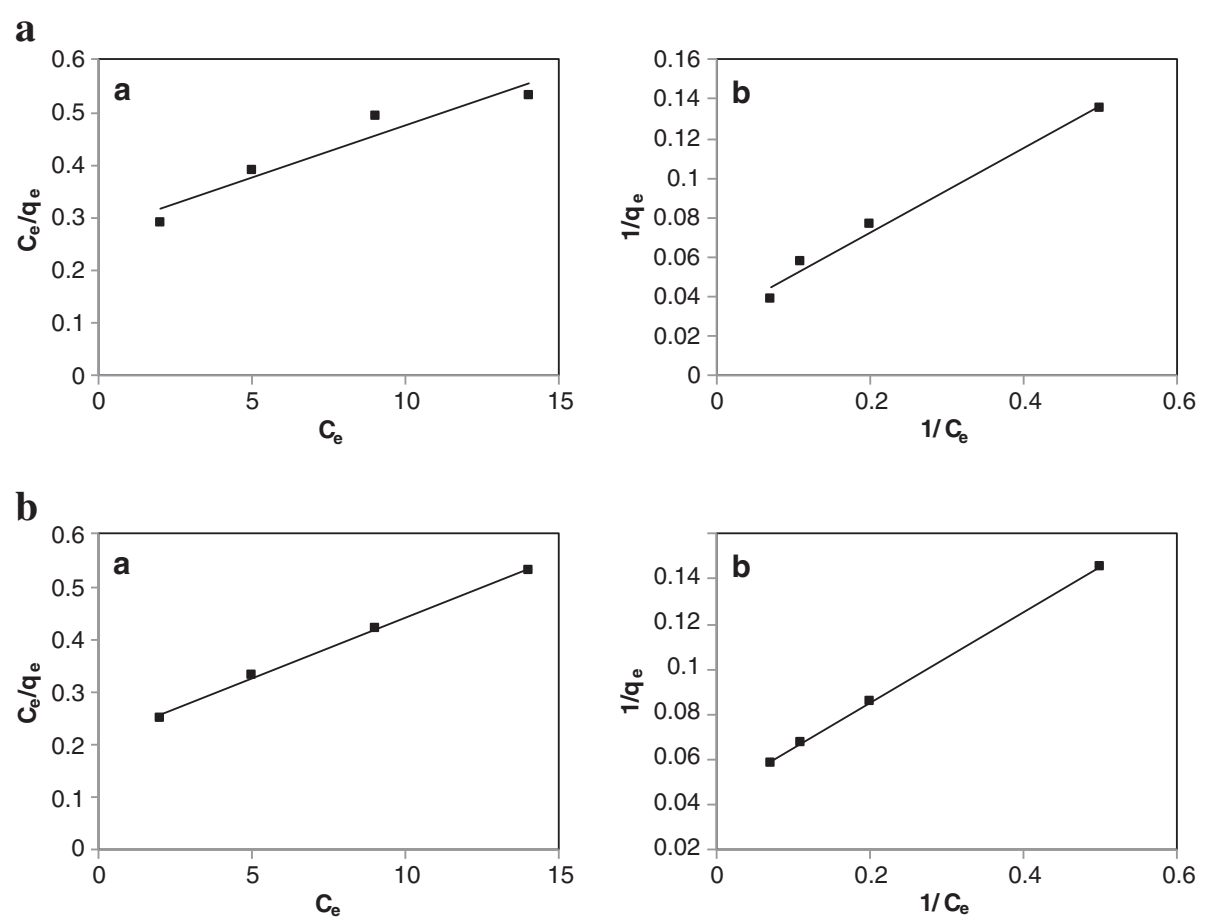

Figure 6 Langmuir plots. (a) Langmuir plots (Type 1A; Type 2B) for EtBr removal by SWCNTs. (b) Langmuir plots (Type 1A; Type 2B) for EtBr removal by NZVI. 
bound at high $C_{\mathrm{e}}(\mathrm{mg} / \mathrm{g})$, and $K_{\mathrm{L}}$ is a constant related to the affinity of the binding sites $(\mathrm{L} / \mathrm{mg})$. The two linear transformations of the Langmuir isotherm is often expressed as Equation 2 (Type1) and Equation 3 (Type 2):

$$
\begin{aligned}
& \frac{C_{e}}{q_{e}}=\frac{1}{K_{\mathrm{L}} q_{\mathrm{m}}}+\frac{C_{e}}{q_{\mathrm{m}}}, \\
& \frac{1}{q_{\mathrm{e}}}=\frac{1}{q_{\mathrm{m}}}+\cdot \frac{1}{K_{L} q_{\mathrm{m}} C_{\mathrm{e}}},
\end{aligned}
$$

The essential characteristics of the Langmuir equation can be expressed in terms of a dimensionless separation factor, $R_{\mathrm{L}}$, defined by [19]:

$$
R_{\mathrm{L}}=\frac{1}{1+K C_{0}},
$$

where $C_{0}$ is the initial EtBr concentration $(\mathrm{mg} / \mathrm{L}) . R_{\mathrm{L}}$ values indicate the type of isotherm to be irreversible $\left(R_{\mathrm{L}}=0\right)$, favorable $\left(0<\mathrm{R}_{\mathrm{L}}<1\right)$, linear $\left(R_{\mathrm{L}}=1\right)$, or unfavorable $\left(R_{L}>1\right)$. The empirical Freundlich isotherm based on sorption on a heterogeneous surface is given by Equation 5 [20]:

$$
q_{\mathrm{e}}=K_{\mathrm{F}} C_{\mathrm{e}}^{1 / n},
$$

or can be written in linearized form (Equation 6) as:

$$
\ln q_{\mathrm{e}}=\ln K_{\mathrm{F}}+\frac{1}{n} \ln C_{\mathrm{e}},
$$

where $K_{\mathrm{F}}$ and $n$ are the Freundlich constants characteristic of the system. $K_{\mathrm{F}}$ and $n$ are indicators of adsorption capacity and adsorption intensity, respectively. $q_{\mathrm{e}}$ is the equilibrium $\mathrm{EtBr}$ concentration in solid phase $(\mathrm{mg} / \mathrm{g})$, and $C_{\mathrm{e}}$ is the equilibrium $\mathrm{EtBr}$ concentration in liquid phase $(\mathrm{mg} / \mathrm{L})$. Temkin isotherm contains a factor that explicitly takes into the account the adsorbing species-adsorbent interactions. The Temkin equation is given as [21]:

$$
q_{\mathrm{e}}=\frac{R T}{b} \ln K_{T} C_{\mathrm{e}},
$$

which can be linearized as:

$$
q_{\mathrm{e}}=B_{T} \ln K_{T}+B_{T} \ln C_{\mathrm{e}},
$$

where $B_{T}=R T / b, T(\mathrm{~K})$ is the absolute temperature, $R$ $\left(8.314 \mathrm{~J} / \mathrm{mol}\right.$ ) is the universal gas constant, $K_{T}$ (per milligram) is the equilibrium binding constant, and $b(\mathrm{~J} / \mathrm{mol})$ is related to the heat of adsorption. The isotherm constants $K_{T}$ and $B_{T}$ are calculated from the slope and intercept of the $q_{\mathrm{e}}$ versus $\ln C_{\mathrm{e}}$ plot. The plots of linearized Langmuir, Freundlich, and Temkin isotherms are illustrated in Figures 6, 7, and 8, respectively. Parameters of the three isotherms were calculated and listed in Table 1. Based on the values of $R^{2}$, it can be concluded that the Langmuir isotherm best fits the equilibrium data. The

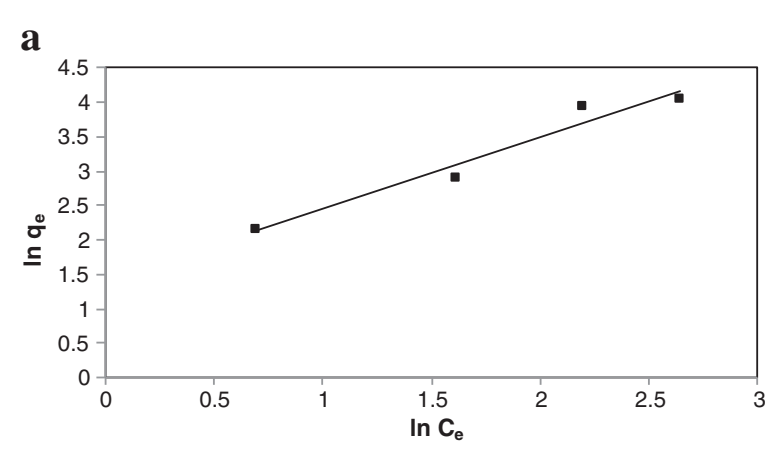

b

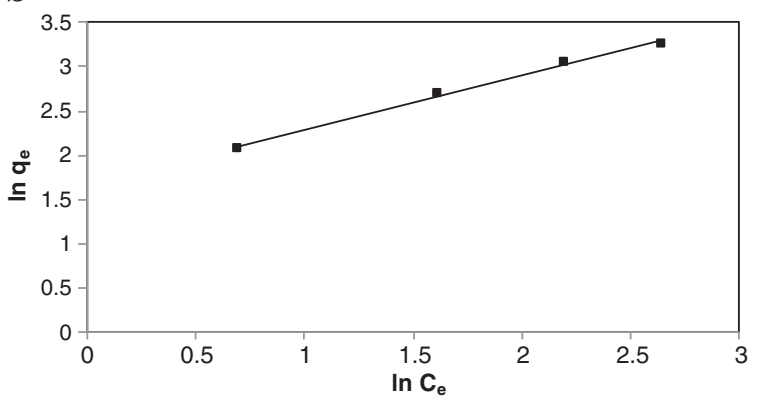

Figure 7 Freundlich plots. (a) Freundlich plots for EtBr adsorption by SWCNTs. (b) Freundlich plots for EtBr adsorption by NZVI.

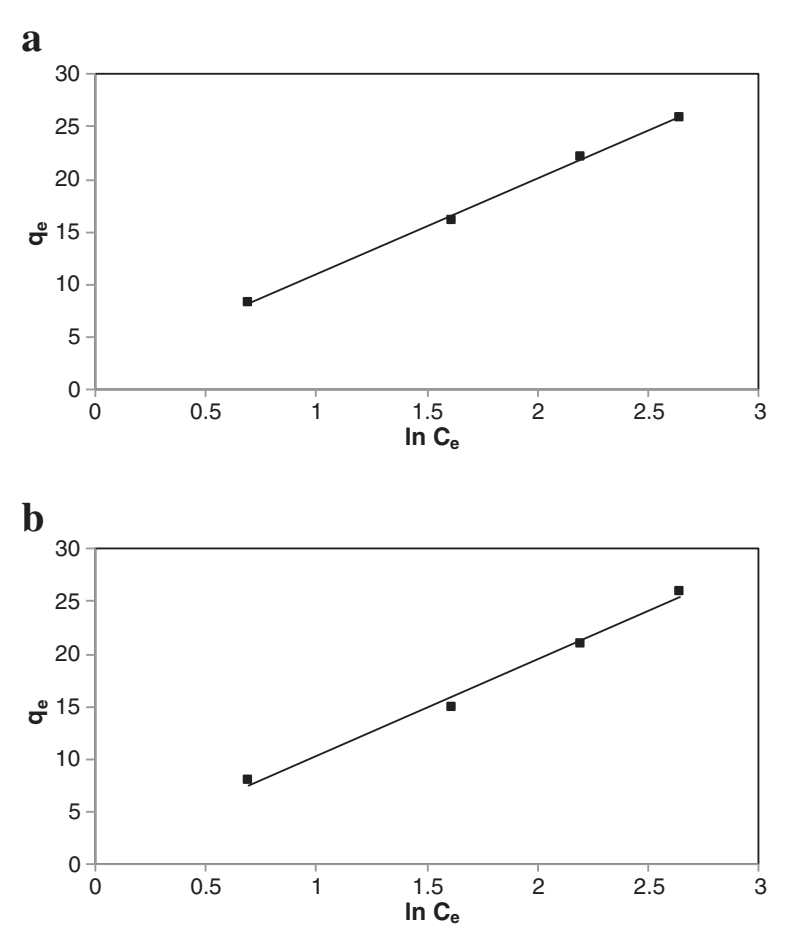

Figure 8 Temkin plots. (a) Temkin plots for EtBr adsorption by SWCNTs. (b) Temkin plots for EtBr adsorption by NZVI. 
Table 1 Isotherm parameters for the adsorption of EtBr by SWCNTs

\begin{tabular}{llllllllllllll}
\hline Langmuir (Type 1) & \multicolumn{4}{c}{ Langmuir (Type 2) } & \multicolumn{3}{c}{ Freundlich } & \multicolumn{3}{c}{ Temkin } \\
\hline$K_{\mathrm{L}}(\mathrm{L} / \mathrm{g})$ & $q_{\mathrm{m}}(\mathrm{mg} / \mathrm{g})$ & $R^{2}$ & $R_{\mathrm{L}}$ & $K_{\mathrm{L}}(\mathrm{L} / \mathrm{g})$ & $q_{\mathrm{m}}(\mathrm{mg} / \mathrm{g})$ & $R^{2}$ & $R_{\mathrm{L}}$ & $K_{\mathrm{F}}(\mathrm{mg} / \mathrm{g}) /(\mathrm{mg} / \mathrm{L})^{1 / n}$ & $n$ & $R^{2}$ & $K_{\mathrm{T}}(\mathrm{m} / \mathrm{g})$ & $b(\mathrm{~J} / \mathrm{mol})$ & $R^{2}$ \\
0.2001 & 45.111 & 0.9994 & 0.5 & 0.1186 & 42.160 & 0.9994 & 0.6 & 5.4286 & 1.733 & 0.9955 & 1.1370 & 270.01 & 0.9990 \\
\hline
\end{tabular}

maximum adsorption capacity $\left(q_{\mathrm{m}}\right)$ of adsorbent calculated from Langmuir isotherm defines the total capacity of the adsorbent for EtBr. The values of $R_{\mathrm{L}}$ calculated from Equation 4 are listed in Table 2 . The $R_{\mathrm{L}}$ values are between 0 and 1 , and the adsorption process is favorable. The fact that the Langmuir isotherm fits the experimental data very well may be due to the homogeneous distribution of active sites on the SWCNTs and NZVI surface because application of the Langmuir equation involves the assumption that the surface were homogeneous.

\section{Conclusions}

The removal of ethidium bromide by SWCNTs and nanoparticle zero valent iron were studied in a batch system with respect to the temperature, adsorbent dose, and contact time. Removal of $\mathrm{EtBr}$ from aqueous solution was possible using SWCNTs and NZVI surfaces. It was seen that maximum adsorption takes place after 5 to $7 \mathrm{~min}$. The optimum doses of adsorbents were $30 \mathrm{mg}$ for NZVI. The Langmuir, Freundlich, and Temkin isotherm models provided the best fits to predict the adsorption for the EtBr by SWCNTs and NZVI surfaces. From the above results, we conclude that the adsorbent NZVI was effective in removing $\mathrm{EtBr}$ from aqueous solution. Also, the removal of EtBr by SWCNT surfaces was more effective than that of NZVI surfaces.

\section{Methods}

\section{Materials}

Ethidium bromide was supplied by Merck, Darmstadt, Germany (maximum purity available). All solutions were prepared with deviations of less than $\pm 0.1 \%$ from the desired concentrations. SWCNTs (Armchair $(6,6)$, purity $>95$; diameter, 1 to $2 \mathrm{~nm}$; length, 5 to $30 \mathrm{~nm}$; surface area, $400 \mathrm{~m}^{2} / \mathrm{g}$; and manufacturing method, catalytic chemical vapor deposition).

\section{Preparation of NZVI particles}

NZVI particles were prepared by liquid-phase reduction method. All solvents were degassed and saturated for 30 min with $\mathrm{N}_{2}$ before use. NZVI was synthesized by adding $1 \mathrm{M} \mathrm{NaBH}_{4}$ solution into $0.5 \mathrm{M} \mathrm{FeCl}_{3}$ solution during vigorous stirring under $\mathrm{N}_{2}$ atmosphere. The mixture's color turned from red brown to light yellow and then eventually to black. At the same time, the mixture gradually produced more black grain particles in the three-neck flask. Ferric iron $\left(\mathrm{Fe}^{+3}\right)$ was reduced to elemental iron according to the following reaction:

$$
\begin{aligned}
& 4 \mathrm{Fe}^{+3}+3 \mathrm{BH}_{4}+9 \mathrm{H}_{2} \mathrm{O} \rightarrow 4 \mathrm{Fe}^{0}(s)+3 \mathrm{H}_{2} \mathrm{BO}_{3}{ }^{-}(\mathrm{aq}) \\
& \quad+12 \mathrm{H}^{+}+6 \mathrm{H}_{2}
\end{aligned}
$$

Then, black NZVI particles were vacuum-filtered and washed with deionized water and 1:1 $(V / V)$ ethanol/acetone; doing so prevented the NZVI from oxidizing, and then, resulting gray-black solid was dried under nitrogen atmosphere before use.

\section{Batch equilibrium studies}

Adsorption experiments were carried out by agitating $50 \mathrm{mg}$ of SWCNTs and NZVI for each individually in aqueous solution with $30 \mathrm{ml}$ of EtBr solution of desired concentration for each surfaces (SWCNTs and NZVI) and $\mathrm{pH}$ at $180 \mathrm{rpm}, 25^{\circ} \mathrm{C}$ in a thermostated mechanical shaker (ORBITEK, Chennai). Concentration of EtBr was estimated spectrophotometrically by monitoring the absorbance at $274 \mathrm{~nm}$ using a UV-vis spectrophotometer (Hitachi model 8543, Chiyoda-ku, Japan).

The effect of adsorbent dosage was studied by agitating $30 \mathrm{~mL}$ of EtBr solutions with different adsorbent doses (10 to $70 \mathrm{mg}$ ) at equilibrium time. The amounts of EtBr adsorbed by the adsorbent were calculated using the following equation:

$$
\frac{\left(C_{0}-C_{\mathrm{t}}\right) V}{W}
$$

where $C_{0}$ is the initial EtBr concentration, $C_{\mathrm{t}}$ is the EtBr concentration $(\mathrm{mg} / \mathrm{L})$ at any time, $V$ is the volume of solu-

\begin{tabular}{|c|c|c|c|c|c|c|c|c|c|c|c|c|c|}
\hline \multicolumn{4}{|c|}{ Langmuir (Type 1) } & \multicolumn{4}{|c|}{ Langmuir (Type 2) } & \multicolumn{3}{|l|}{ Freundlich } & \multicolumn{3}{|l|}{ Temkin } \\
\hline$\overline{K_{\mathrm{L}}(\mathrm{L} / \mathrm{g})}$ & $q_{\mathrm{m}}(\mathrm{mg} / \mathrm{g})$ & $R^{2}$ & $R_{\mathrm{L}}$ & $K_{\mathrm{L}}(\mathrm{L} / \mathrm{g})$ & $q_{m}(\mathrm{mg} / \mathrm{g})$ & $R^{2}$ & $R_{\mathrm{L}}$ & $K_{\mathrm{F}}(\mathrm{mg} / \mathrm{g}) /(\mathrm{mg} / \mathrm{L})^{1 / n}$ & $n$ & $R^{2}$ & $K_{\mathrm{T}}(\mathrm{m} / \mathrm{g})$ & $b(\mathrm{~J} / \mathrm{mol})$ & $R^{2}$ \\
\hline 0.1106 & 43.290 & 0.9981 & 0.4 & 0.1186 & 42.160 & 0.9991 & 0.5 & 5.3275 & 1.626 & 0.9940 & 1.1261 & 264.94 & 0.9911 \\
\hline
\end{tabular}
tion $(L)$, and $W$ is the mass of the adsorbents $(g)$.

Table 2 Isotherm parameters for the adsorption of EtBr by NZVI 


\section{Competing interests}

The authors declare that they have no competing interests.

\section{Authors' contributions}

FN carried out the result analysis, participated to draft the manuscript and in the manuscript elaboration, carried out the experiments, and obtained most of the experimental images. MN, KZ, and AF coordinated the project, discussed the results, and helped to draft the manuscript. All authors read and approved the final manuscript.

\section{Acknowledgements}

The authors would like to thank the Islamic Azad University Roudehen Branch for their financial support.

\section{Author details}

${ }^{1}$ Department of Chemistry, Roudehen Branch, Islamic Azad University, Roudehen, Iran. ${ }^{2}$ Department of Virology, School of Public Health and Institute of Health Research, Tehran University of Medical Sciences, Tehran, Iran. ${ }^{3}$ Department of Chemistry, Science and Research Branch, Islamic Azad University, Tehran, Iran. ${ }^{4}$ Department of Chemistry, Shahid Beheshti University, Evin, Tehran, Iran. ${ }^{5}$ Department of Chemistry, Shahre-Qods Branch, Islamic Azad University, Tehran, Iran.

Received: 27 May 2013 Accepted: 28 May 2013

Published: 29 July 2013

\section{References}

1. Lunn, G, Sansone, EB: Ethidium bromide: destruction and decontamination of solutions. Anal Biochem 162, 453-458 (1987)

2. Bountiff, L, Levantis, P, Oxford, J: Electrophoretic Analysis of Nucleic Acids Isolated from Scrapie-infected Hamster Brain. J Gen Virol 77, 2371-2378 (1996)

3. Bailey, SE, Olin, TJ, Bricka, RM, Adrian, DD: A review of potentially low-cost sorbents for heavy metals. Water Res 33, 2469-2479 (1999)

4. Uzum, C, Shahwan, T, Eroglu, AE, Lieberwirth, I, Scott, TB, Hallam, KR: Application of zero-valent iron nanoparticles for the removal of aqueous $\mathrm{CO}^{2+}$ ions under various experimental conditions. Chem Eng J 144, 213-220 (2008)

5. Cantrell, KJ, Kaplan, DI, Wietsma, TW: Zero-valent iron for the in situ remediation of selected metals in groundwater. J Hazard Mater 42, 201-212 (1995)

6. Cho, HH, Park, JW: Sorption and reduction of tetrachloroethylene with zero valent iron and amphiphilic molecules. Chemosphere 64, 1047-1052 (2006)

7. Dombek, T, Dolan, E, Schultz, J, Klarup, D: Rapid reductive dechlorination of atrazine by zero-valent iron under acidic conditions. Environ Pollut 111, 21-27 (2001)

8. Ghauch, A, Rima, J, Amine, C, Martin-Bouyer, M: Rapid treatment of water contamined with atrazine and parathion with zero-valent iron. Chemosphere 39, 1309-1315 (1999)

9. Noubactep, C: Characterizing the discoloration of methylene blue in $\mathrm{Fe}^{0}$ \% $\mathrm{H}_{2} \mathrm{O}$ systems. J Hazard Mater 166, 79-87 (2009)

10. Noubactep, C, Kurth, AMF, Sauter, M: Evaluation of the effects of shaking intensity on the process of methylene blue discoloration by metallic iron. J Hazard Mater 169, 1005-1011 (2009)

11. Noubactep, C: Characterizing the reactivity of metallic iron upon methylene blue discoloration in $\mathrm{Fe} / / \mathrm{MnO}_{2} / \mathrm{H}_{2} \mathrm{O}$ systems. J Hazard Mater $168,1613-1616$ (2009)

12. Li, XQ, Elliott, DW, Zhang, WX: Zero-Valent Iron Nanoparticles for Abatement of Environmental Pollutants: Materials and Engineering Aspects. Crit. Rev. Solid State Mater. Sci. 31, 111-122 (2006)

13. Noubactep, C: A Critical review on the process of contaminant removal in fe0-h2o systems. Environ. Technol. 29, 909-920 (2008)

14. Noradoun, CE, Cheng, IF: EDTA Degradation Induced by Oxygen Activation in a Zerovalent Iron/Air/Water System. Environ. Part Sci Technol 39, 7158-7163 (2005)

15. Wang, H, Zhou, A, Peng, F, Yu, H, Yang, J: Mechanism study on adsorption of acidified multi-walled carbon nanotubes to $\mathrm{Pb}(\mathrm{II})$. J Colloid Interface Sci 316, 277-283 (2007)

16. Lu, C, Chiu, H, Liu, C: Removal of zinc(II) from aqueous solution by purified carbon nanotubes: Kinetics and equilibrium studies. Ind Eng Chem Res 45, 2850-2855 (2006)

17. Feng, J, Lim, TT: Iron-mediated reduction rates and pathways of halogenated methanes with nanoscalePd/Fe: Analysis of linear free energy relationship. Chemosphere 66, 1765-1774 (2007)
18. Langmuir, I: The adsorption of gases on plane surfaces of glass, mica and platinum. J Am Chem Soc 40, 1361-1368 (1918)

19. Mahmoodi, NM, Arami, M: Modeling and sensitivity analysis of dyes adsorption onto natural adsorbent from colored textile wastewater. J Appl Polym Sci 109, 4043-4048 (2008)

20. Freundlich, HMF: Uber die adsorption in I osungen (adsorption in solution). J Phys Chem 57, 385-470 (1906)

21. Moradi, O, Zare, K, Monajjemi, M, Yari, M, Aghaie, H: The studies of equilibrium and thermodynamic adsorption of $\mathrm{Pb}(\mathrm{II}), \mathrm{Cd}(\mathrm{II})$ and $\mathrm{Cu}(\mathrm{II})$ ions from aqueous solution on SWCNTs and SWCNT-COOH surfaces. Fullerenes, Nanotubes, and Carbon Nanostructures 18, 285-302 (2010)

doi:10.1186/2193-8865-3-60

Cite this article as: Najafi et al:: Removal of ethidium bromide by carbon nanotube in aqueous solution: isotherms, equilibrium mechanism studies, and its comparison with nanoscale of zero valent iron as adsorbent. Journal Of Nanostructure in Chemistry 2013 3:60

\section{Submit your manuscript to a SpringerOpen ${ }^{\circ}$ journal and benefit from:}

- Convenient online submission

- Rigorous peer review

- Immediate publication on acceptance

- Open access: articles freely available online

- High visibility within the field

- Retaining the copyright to your article

Submit your next manuscript at $>$ springeropen.com 